\title{
Music education for improving reading skills in children and adolescents with dyslexia (Review)
}

Cogo-Moreira H, Andriolo RB, Yazigi L, Ploubidis GB, Brandão de Ávila CR, Mari JJ

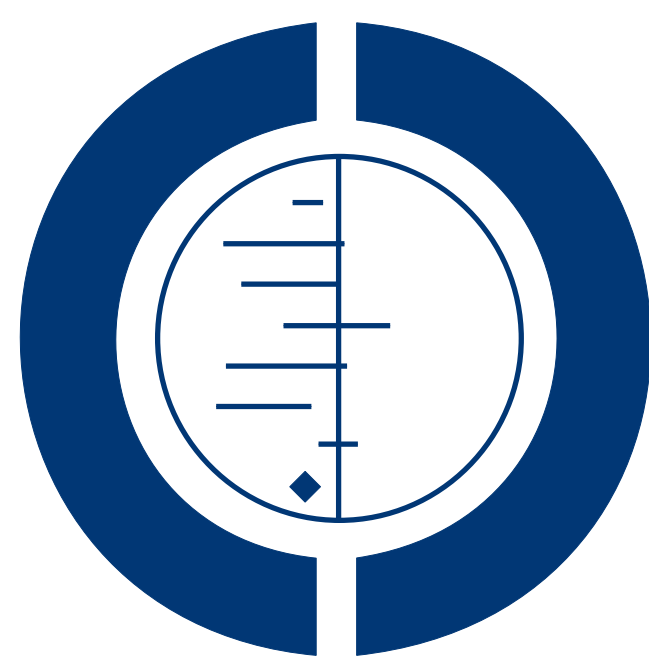

\section{THE COCHRANE COLLABORATION $^{\circledR}$}

This is a reprint of a Cochrane review, prepared and maintained by The Cochrane Collaboration and published in The Cochrane Library 2012, Issue 8

http://www.thecochranelibrary.com

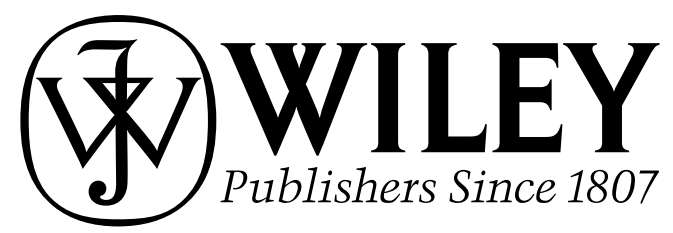

Music education for improving reading skills in children and adolescents with dyslexia (Review)

Copyright $\odot 2012$ The Cochrane Collaboration. Published by John Wiley \& Sons, Ltd. 
TABLE OF CONTENTS

HEADER . . . . . . . . . . . . . . . . . . . . . . . . . . . . . . . . . . . . . . . 1

ABSTRACT . . . . . . . . . . . . . . . . . . . . . . . . . . . . . . . . . . . . . . . . . . . . . . .

PLAIN LANGUAGE SUMMARY . . . . . . . . . . . . . . . . . . . . . . . . . . . . . . . . . . . 2

BACKGROUND . . . . . . . . . . . . . . . . . . . . . . . . . . . . . . . . . . . . . 2

OBJECTIVES . . . . . . . . . . . . . . . . . . . . . . . . . . . . . . . . . . . . .

METHODS . . . . . . . . . . . . . . . . . . . . . . . . . . . . . . . . . . . . . . .

RESULTS . . . . . . . . . . . . . . . . . . . . . . . . . . . . . . . . . . . . . . 6

Figure 1. . . . . . . . . . . . . . . . . . . . . . . . . . . . . . . . . . . 7

DISCUSSION . . . . . . . . . . . . . . . . . . . . . . . . . . . . . . . . . . . . . .

AUTHORS' CONCLUSIONS . . . . . . . . . . . . . . . . . . . . . . . . . . . . . . . . . .

ACKNOWLEDGEMENTS . . . . . . . . . . . . . . . . . . . . . . . . . . . . . . . . . . . . . . .

REFERENCES . . . . . . . . . . . . . . . . . . . . . . . . . . . . . . . . . . . . . . 9

CHARACTERISTICS OF STUDIES . . . . . . . . . . . . . . . . . . . . . . . . . . . . . . . . . . . . . .

DATA AND ANALYSES . . . . . . . . . . . . . . . . . . . . . . . . . . . . . . . . . . . . . 14

APPENDICES . . . . . . . . . . . . . . . . . . . . . . . . . . . . . . . . . . . . . . 14

HISTORY . . . . . . . . . . . . . . . . . . . . . . . . . . . . . . . . . . . . . . . 23

CONTRIBUTIONS OF AUTHORS . . . . . . . . . . . . . . . . . . . . . . . . . . . . . . . . . . . . 24

DECLARATIONS OF INTEREST . . . . . . . . . . . . . . . . . . . . . . . . . . . . . . . . . . 24

SOURCES OF SUPPORT . . . . . . . . . . . . . . . . . . . . . . . . . . . . . . . . . . . . . . . . .

INDEX TERMS . . . . . . . . . . . . . . . . . . . . . . . . . . . . . . . . . . . . . 24

Music education for improving reading skills in children and adolescents with dyslexia (Review)

Copyright $\odot 2012$ The Cochrane Collaboration. Published by John Wiley \& Sons, Ltd. 


\title{
[Intervention Review] \\ Music education for improving reading skills in children and adolescents with dyslexia
}

\author{
Hugo Cogo-Moreira ${ }^{1}$, Régis B Andriolo ${ }^{2}$, Latife Yazigi ${ }^{1}$, George B Ploubidis ${ }^{3}$, Clara Regina Brandão de Ávila ${ }^{4}$, Jair J Mari ${ }^{1}$ \\ ${ }^{1}$ Department of Psychiatry, Universidade Federal de São Paulo, São Paulo, Brazil. ${ }^{2}$ Department of Public Health, Universidade do \\ Estado do Pará, Belém, Brazil. ${ }^{3}$ Department of Population Studies, London School of Hygiene and Tropical Medicine, London, UK. \\ ${ }^{4}$ Department of Speech-Language and Hearing Pathology, Universidade Federal de São Paulo, São Paulo, Brazil \\ Contact address: Hugo Cogo-Moreira, Department of Psychiatry, Universidade Federal de São Paulo, Rua Borges Lagoa, 570, São \\ Paulo, Sao Paulo, 04038-030, Brazil. hugocogobr@gmail.com.
}

Editorial group: Cochrane Developmental, Psychosocial and Learning Problems Group.

Publication status and date: New, published in Issue 8, 2012.

Review content assessed as up-to-date: 6 June 2012.

Citation: Cogo-Moreira H, Andriolo RB, Yazigi L, Ploubidis GB, Brandão de Ávila CR, Mari JJ. Music education for improving reading skills in children and adolescents with dyslexia. Cochrane Database of Systematic Reviews 2012, Issue 8. Art. No.: CD009133. DOI: 10.1002/14651858.CD009133.pub2.

Copyright (C) 2012 The Cochrane Collaboration. Published by John Wiley \& Sons, Ltd.

\begin{abstract}
A B S T R A C T
Background

Dyslexia (or developmental dyslexia or specific reading disability) is a specific learning disorder that has a neurobiological origin. It is marked by difficulties with accurate or fluent recognition of words and poor spelling in people who have average or above average intelligence and these difficulties cannot be attributed to another cause, for example, poor vision, hearing difficulty, or lack of socioenvironmental opportunities, motivation, or adequate instruction. Studies have correlated reading skills with musical abilities. It has been hypothesized that musical training may be able to remediate timing difficulties, improve pitch perception, or increase spatial awareness, thereby having a positive effect on skills needed in the development of language and literacy.
\end{abstract}

\section{Objectives}

To study the effectiveness of music education on reading skills (that is, oral reading skills, reading comprehension, reading fluency, phonological awareness, and spelling) in children and adolescents with dyslexia.

\section{Search methods}

We searched the following electronic databases in June 2012: CENTRAL (2012, Issue 5), MEDLINE (1948 to May Week 42012 ), EMBASE (1980 to 2012 Week 22), CINAHL (searched 7 June 2012), LILACS (searched 7 June 2012), PsycINFO (1887 to May Week 5 2012), ERIC (searched 7 June 2012), Arts and Humanities Citation Index (1970 to 6 June 2012), Conference Proceedings Citation Index - Social Sciences and Humanities (1990 to 6 June 2012), and WorldCat (searched 7 June 2012). We also searched the WHO International Clinical Trials Registry Platform (ICTRP) and reference lists of studies. We did not apply any date or language limits.

\section{Selection criteria}

We planned to include randomized controlled trials. We looked for studies that included at least one of our primary outcomes. The primary outcomes were related to the main domain of the reading: oral reading skills, reading comprehension, reading fluency, phonological awareness, and spelling, measured through validated instruments. The secondary outcomes were self esteem and academic achievement.

Music education for improving reading skills in children and adolescents with dyslexia (Review)

Copyright $\odot 2012$ The Cochrane Collaboration. Published by John Wiley \& Sons, Ltd. 


\section{Data collection and analysis}

Two authors (HCM and RBA) independently screened all titles and abstracts identified through the search strategy to determine their eligibility. For our analysis we had planned to use mean difference for continuous data, with $95 \%$ confidence intervals, and to use the random-effects statistical model when the effect estimates of two or more studies could be combined in a meta-analysis.

\section{Main results}

We retrieved 851 references via the search strategy. No randomized controlled trials testing music education for the improvement of reading skills in children with dyslexia could be included in this review.

\section{Authors' conclusions}

There is no evidence available from randomized controlled trials on which to base a judgment about the effectiveness of music education for the improvement of reading skills in children and adolescents with dyslexia. This uncertainty warrants further research via randomized controlled trials, involving a interdisciplinary team: musicians, hearing and speech therapists, psychologists, and physicians.

\section{PLAIN LANGUAGE SUMMARY}

\section{Music education for improving reading skills in children and adolescents with dyslexia}

Despite having average or above average intelligence, people with dyslexia (or developmental dyslexia or specific reading disability) have difficulties with accurate or fluent recognition of words (or both) and poor spelling that cannot be attributed to another cause, such as poor vision or hearing or a lack of teaching or motivation. As a consequence of their difficulties, children and adolescents with dyslexia may experience early academic failure. Some studies suggest that reading skills and musical abilities might be related and that musical training may be able to help in the development of language and literacy skills. As information about the effectiveness of musical learning for children and adolescents is lacking, we searched widely for high-quality evidence in the form of randomized controlled trials. We did not find any and so it is not possible for us to reliably assess the advantages (or even disadvantages) of music education for improving the reading skills of dyslexic children. Well-designed research with a large number of participants is required to evaluate potential benefits of musical education for children and adolescents with dyslexia.

\section{B A C K G R O U N D}

\section{Description of the condition}

Dyslexia is a specific learning disorder "with a neurobiological origin...characterized by difficulties with accurate and/or fluent recognition and by poor spelling and decoding" (Lyon 2003). Also known as developmental dyslexia, specific reading disability or specific learning difficulty, dyslexia is a difficulty in learning present in people with average or above average intelligence and not resulting from poor vision, hearing difficulty, lack of socio-environmental opportunities, lack of motivation, or even lack of adequate instruction (Shaywitz 2003). This review does not include dyslexia that is acquired, for example, due to brain injury or due to a condition such as glue ear. Dyslexia is a persistent difficulty, such that "children who fail to read adequately in 1 st grade have a $90 \%$ chance of reading poorly in 4 th grade and a $75 \%$ chance of reading poorly in high school" (Gabrieli 2009). Gabrieli 2009 also points out that the roots of dyslexia begin before initial reading instruction, but it is commonly diagnosed (in the United States) in children aged seven to eight years, by which time the reading difficulties are clearly measurable. According to Lyon 1996, 75\% of children with reading disabilities not identified before the third grade continue to have reading disabilities into the ninth grade, and fewer than two per cent go on to participate in a four-year higher education program after high school.

Dyslexia is considered to have a genetic component (probably $54 \%$ to $75 \%$ ) and has been found to occur in up to $68 \%$ of identical twins and $50 \%$ of individuals who have a parent or sibling with dyslexia (Pennington 1996). Its prevalence is between $4 \%$ and $10 \%$ of school-aged children (Shaywitz 1998; Bishop 2004; Blomert 2005), depending on the criteria applied (for example, Zoccolotti 2010 identified 17 types of developmental dyslexia). The main theory about its cause is related to a deficit in phonolog- 
ical processing (Bradley 1978; Wagner 1987; Ramus 2003), and more recent functional studies have revealed a hypoactivation of the left temporoparietal cortex when dyslexic children are compared with typically developing readers (Hoeft 2007). Other authors, such as Kronbichler 2008 and Pernet 2009, have reported a reduction in gray and white matter in the brains of children and adults with dyslexia.

Reading can be thought of as having different components (or 'domains') and dyslexic children have problems with some of these components, such as phonological awareness and reading fluency. Phonological awareness is the ability to attend to and manipulate the sounds in words (Stanovich 1986), segmenting each individual speech sound. This awareness is important when learning to read in alphabetic script such as Spanish, German, or English (Goswami 1990; Hulme 2002; Muter 2004). Reading fluency is most often defined as the ability to read text quickly, accurately, and with appropriate expression (National Reading Panel 2000; Kuhn 2003) and oral reading fluency has been shown to be related to comprehension (Fuchs 1988; Fuchs 2001; Jenkins 2003). Dyslexic children often have difficulty with this reading fluency domain, which results in poor comprehension. Recently, this domain was identified as an area of difficulty for individuals with dyslexia by the International Dyslexia Association (Lyon 2003). The reading process is slow and laborious for dyslexic children (Chall 1990) and may be followed by an avoidance of reading and general frustration (Pinnell 1995; Leinonen 2001).

\section{Description of the intervention}

This review is concerned with the potential effect that music education (or musical training - both terms will be used interchangeably in this review) can have on children's reading. Here we consider music education as any methodology of teaching music, whether in a specific center of music teaching (for example, conservatory, Music School) or a music class included in the syllabus of a kindergarten or elementary school. Generally, music education can be described as the process of learning music supervised by a music teacher or a specialist in music education. A music teacher could be defined as someone who has an understanding of music elements (for example, music context, score analysis, musical style, aesthetics) and is competent to teach this to children.

The National Association for Music Education, whose mission is described as " to advance music education by encouraging the study and making of music by all”, has established nine national standards for Music Education (NAfME 2011).

1. Singing, alone and with others, a varied repertoire of music.

2. Performing on instruments, alone and with others, a varied repertoire of music.

3. Improvising melodies, variations, and accompaniments.

4. Composing and arranging music within specified guidelines.

5. Reading and notating music.
6. Listening to, analyzing, and describing music.

7. Evaluating music and music performances.

8. Understanding relationships between music, the other arts, and disciplines outside the arts.

9. Understanding music in relation to history and culture.

There are different approaches to music education (Suzuki, Dalcroze, Orff, and Kodály) and each one may require specific music education training as the teaching concepts differ. Students are generally exposed to key elements of music such as rhythm, melody, harmony, and timbre regardless of the approach, although each one has its own particular form. The main approaches to music education currently are:

- Suzuki Method: developed by Shin' ichi Suzuki (18981998), a Japanese educationist and violin teacher, who believed that children could learn musical skills at an early age, initially through listening, and observed the way young children acquire language through hearing others speak (Mills 1973). Just as children learn to speak before learning to read, Suzuki advocated a delay in teaching musical notation until there was an adequate grounding in playing skills and the development of musical memory. In the Suzuki Method, the children are taught in groups rather than individually, encouraging co-operation and teamwork.

- Dalcroze Method: created by the Swiss musician and educator Emile Jaques-Dalcroze (1869-1950) who developed a system of group music teaching through 'gymnastique rythmique (eurhythmics). This system uses physical exercises together with the music class to help students respond physically and aesthetically to music (Henry 1958).

- The German Orff-Schulwerk system, created by Carl Orff, combines choral singing, aural training, movement, improvisation, and activities that use specially designed pitched and non-pitched percussion instruments. Five books of teaching materials, Musik für Kinder (1950-54), exemplify ways of making what is called "elementary music". Various arrangements of folk songs and traditional melodies are intended as models or suggestions for teachers rather than a comprehensive scheme (Keller 1963).

- Kodály's principles of music teaching (Hungarian Method) are in many ways similar to those of Orff, but the Hungarian approach is more fundamentally choral. Concerned with the development of inner hearing and musical literacy, and determined to improve the musical life of the nation, Kodály drew on his country's folk song tradition, which he combined with art music using the pitch teaching principles of Curwen, hand signs, and the rhythmic language of the Galin-Paris-Chevé movement (Sándor 1975).

In music education, each one of the musical elements (rhythm, timbre, aesthetic, harmony, pitch) can be studied separately, using different strategies in order to stimulate and develop children's perception of them as shown by Moreno 2009. The frequency and length of sessions varies between studies. Research has been con- 
ducted using different types of musical activities, such as singing (all the children together singing the same musical passage, in unison, or in canon structure), rhythm (via corporal movement or corporal percussion), and instrumental practice (which could be highly technical learning of a specific musical instrument or using the instrument in an informal way with the focus on the interaction between the sound and the child and not on technical proficiency).

It is important to emphasize that music education is not the same as music therapy, despite the fact that both use music as an intervention and both are often provided in the same setting. Music therapy is a psychotherapeutic method that uses musical interaction as a means of communication and expression and aims to help people with mental illness to develop relationships and to address issues they may not be able to address using words alone (Gold 2004; Gold 2009). Also, it is important to emphasize that the process of musical learning is not necessarily as narrow as the traditional view, which focused on the technical mastery of a particular instrument. The approaches listed above consider musical learning to be a general learning process, not only the formal technicalities of learning to play an instrument or even decoding sheet music. Green 2008 identified different principles of informal music learning, for example, starting with music chosen by the learners themselves, peer and/or self directed learning, integration of improvisation, performance, listening, and composition.

\section{How the intervention might work}

Studies correlate children's ability to read with their ability to distinguish pitches accurately (Fisher 2001; Hansen 2002; Schön 2004; Magne 2006; Besson 2007; Marques 2007; Nikjeh 2009), arguing for a strong link between basic auditory perception abilities and reading abilities. Anvari 2002 found significant correlations between music skills, phonological awareness, and the reading development of four- and five-year-old children. The connections between reading achievement and two distinct styles of music education have been investigated: (a) Orff, Kodály, or Dalcroze instruction, which stresses multisensory, developmental group activities including singing or playing percussion (Hurwitz 1975), or (b) participation in choral, band, or orchestral ensembles requiring music reading skills and extensive practice to achieve competence (Douglas 1994). Nikjeh 2009 observed that trained musicians, when compared with non-musicians, showed more efficient neural detection of pure tones and harmonic tones, and demonstrated superior memory for acoustic features of pure tones, harmonic tones, and speech. Growing evidence from a range of research disciplines suggests that musical experience can have a positive effect on language and literacy abilities (Douglas 1994; Sutton 1995; Kilgour 2000). In addition, there is increasing recognition of the numerous shared features of music and language, from developmental characteristics to perceptual processes and common neural substrates (Sloboda 1985; Patel 1998; Patel 2008).
According to Schlaug 2005, playing an instrument requires a range of skills, including reading a symbolic system (musical notation) and translating it into sequential, bimanual motor activity dependent on multisensory feedback. Learning to read, according to this point of view, could be compared to playing or learning a musical instrument, which requires co-ordination of the eye muscles to follow a single line of printed musical notation (for example, when playing the violin, viola, bass, or flute) or a conjunction of lines (for example, when playing the piano, organ, or harpsichord). It is necessary to develop a spatial orientation to play each musical note from the sheet music and correlate it with a specific position on the instrument, which is comparable in this case with words and letters that together form a larger structure.

Temporal cues are important in speech perception (Martin 1986), and temporal fluency is a key factor in reading proficiency (Hanes 1986). More specifically, according to Huss 2010, musical metrical sensitivity has been found to be a predictor of phonological awareness in reading development. Besson 2007 concluded that "a set of common processes may be responsible for pitch processing in music and in speech". It would be reasonable to assume that if pitch - the perceptual attribute that corresponds to sound frequency - is an important acoustic parameter for both music and speech perception, then increased efficiency in pitch processing due to musical experience should also improve pitch perception in speech.

Overy (Overy 2000; Overy 2003), on the other hand, focused her hypothesis on the temporal processing component of reading. According to this author, dyslexic people have particular difficulties with skills involving accurate or rapid timing, including musical timing skills. It has been hypothesized that music education may be able to remediate such timing difficulties, and have a positive effect on perceptual skills that are important in the development of language and literacy skills.

Gabrieli 2009 has pointed out that dyslexic children who retain their benefits after systematic instruction in phonological awareness and decoding strategies improve from year to year, but they do not catch up with the typical reader; according to the same author, improvements are more likely to occur in children who are beginning to read (ages six to eight) than in older children.

\section{Why it is important to do this review}

Several studies have reported benefits of musical training in domains related to language, for example, as verbal memory (Ho 2003), reading (Hurwitz 1975), and processing of lexical stress (Kolinsky 2009), and also mathematical achievements (Cheek 1999) and IQ (intelligence quotient) (Schellenberg 2004), but the knowledge about this topic is non-specific and contradictory. It is therefore important to critically analyze and synthesize the evidence for the effectiveness of music education as a means of improving reading in children who have dyslexia. 


\section{O B J E C T I V E S}

To study the effectiveness of music education on the spectrum of reading skills in children and adolescents with dyslexia.

\section{METHODS}

\section{Criteria for considering studies for this review}

\section{Types of studies}

Randomized controlled trials (including quasi-randomized or cluster-randomized trials).

\section{Types of participants}

Dyslexic children and adolescents attending public and private schools.

\section{Types of interventions}

Any approach of music education as defined below, compared with a waiting list or no treatment control group.

Eligible forms of music education were: individual or group music lessons or musical training with a music advisor or teacher at music school (extracurricular) or at the school where the children are receiving their formal instruction, either as part of the general curriculum or as additional tuition. Children may be exposed to song and tonal or atonal and rhythmic patterns in a natural musical setting or may be exposed to a specific musical methodological approach (for example, Dalcroze Method, Kodaly Method, Suzuki Method, or Orff Approach). They may be encouraged to practise music in small or large groups.

\section{Types of outcome measures}

\section{Primary outcomes}

Because this review is concerned with the impact of musical education on reading skills, we planned to only include studies that reported at least one of the following outcomes. The outcomes of oral reading skills, reading comprehension, reading fluency, phonological awareness, and spelling can be measured through validated instruments, examples of which are detailed below.

- Oral reading skills (for example, Gray Oral Reading Test, Safety Word Inventory and Literacy Screener, Get Ready to Read! (GRTR), Woodcock Reading Mastery Tests (Woodcock 1987)).

- Phonologic awareness (for example, Comprehensive Test of Phonological Processing).
- Reading fluency and comprehension (for example, Test of Oral Reading Fluency (TORF), Retell Fluency (RTF), maze (MZ), written retell (WRT), and sentence verification technique (such as SVT)).

- Nonword reading and spelling (for example, The Graded Nonword Reading and Spelling Test (Snowling 1996)).

- Expressive and receptive vocabulary (for example, Clinical Evaluation of Language Fundamentals (Semel 1986)).

- Phonological processing (for example, Comprehensive Test of Phonological Processing - CTOPP (Wagner 1999) or Rapid Automatized Naming Test (Wolf 2005)).

\section{Secondary outcomes}

- Self esteem.

- Improved academic performance.

We planned examine the outcome data in the short term (up to six months), medium term (between six and 12 months) and long term (more than 12 months).

\section{Search methods for identification of studies}

We ran the searches in May 2011 and updated them in June 2012. We imported records into reference management software, and identified and discarded exact duplicates.

\section{Electronic searches}

We searched the following databases.

- Cochrane Central Register of Controlled Trials (CENTRAL) 2012, Issue 5, part of T he Cochrane Library (searched 7 June 2012)

- MEDLINE, 1948 to May Week 42012 (searched 6 June 2012)

- EMBASE, 1980 to 2012 Week 22 (searched 6 June 2012)

- CINAHL Plus, 1937 to current (searched 7 June 2012)

- PsycINFO, 1887 to May Week 52012 (searched 6 June 2012)

- ERIC, 1966 to current (searched 7 June 2012)

- LILACS, all available years (searched 7 June 2012)

- WorldCat (limited to theses), all available years (searched 7 June 2012)

- Arts and Humanities Citation Index (A\&HCI), 1975 to 6 June 2012 (searched 7 June 2012)

- Social Science Citation Index, 1970 to 6 June 2012 (searched 7 June 2012)

- Conference Proceedings Citation Index - Social Science and Humanities (CCPI-SSH), 1990 to 6 June 2012 (searched 7 June 2012)

- WHO International Clinical Trials Registry Platform (ICTRP) (searched 7 June 2012) 
We developed a search strategy in MEDLINE and added the Cochrane highly sensitive search strategy to identify randomized trials (Lefebvre 2008). We adapted this for other databases (see Appendix 1). We applied no date or language limits.

\section{Searching other resources}

1. Reference lists: we checked references in the identified studies for additional citations.

2. Personal contact: we contacted via email study authors and experts to request any unpublished data.

\section{Data collection and analysis}

\section{Selection of studies}

Two authors (HCM and RBA) independently screened all titles and abstracts identified through the search strategy. We obtained full reports of any title or abstract that seemed likely to meet our inclusion criteria. HCM and RBA independently read all reports to determine their eligibility. We planned to resolve any disagreements by discussion with a third author (JJM); this was not necessary during the first version of this review.

\section{Data extraction and management}

Please see Appendix 2 for a table of methods we had planned to use but were unable to as there were no studies included in the review. We will use these in any update of this review.

\section{RES U L T S}

\section{Description of studies}

See: Characteristics of excluded studies.

\section{Results of the search}

Our search strategy yielded a total of 876 citations after duplicate citations were removed using EndNote. We had explicit criteria (Appendix 3) to guide the selection of studies with potential to be included in our review. Two review authors performed this selection independently (RBA and HCM) and the concordance between them was measured by the Kappa coefficient (KC). The level of agreement was considered low $(\mathrm{KC}=0.227 ; 95 \%$ confidence interval $=0.076$ to 0.378 ) (Latour 1997). The main reason for the divergence was the absence of clear concepts of dyslexia and music education, probably due to the different scientific backgrounds of the review authors. After a meeting where definitions and concepts about dyslexia and music education were clarified and agreed, the whole process was gone through again from the beginning and the Kappa between the authors was 0.89 (95\% confidence interval 0.87 to 0.91 ). Six potential studies seemed to be possibilities for inclusion but were ultimately excluded: Fiveash 1995; Jaarsma 1998; Banks 1999; Overy 2003; Draper 2007; Register 2007. A flow chart detailing the process is in Figure 1. 
Figure I. Study flow diagram

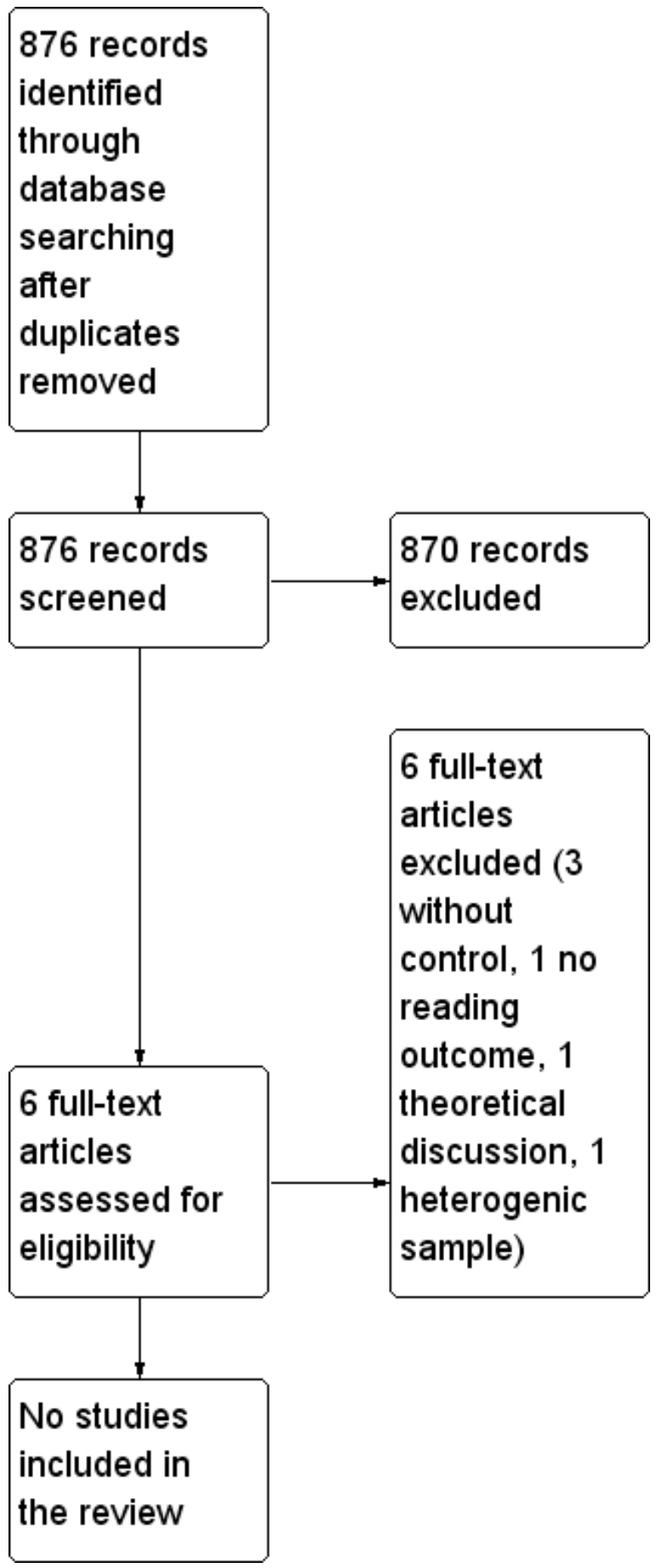




\section{Included studies}

There were no studies that fulfilled our inclusion criteria.

\section{Excluded studies}

Using the clinical condition and the intervention of interest as the criteria for the study selection, six primary studies had the potential to be included since they mentioned musical education for children with dyslexia. However, we excluded them after looking at them in more detail either because they were not a randomized clinical trial or because they did not use any reading skill as an outcome.

\section{Risk of bias in included studies}

Not applicable for this version of the review as we had no included studies.

\section{Effects of interventions}

Not applicable for this version of the review as we had no included studies.

\section{DISCUSSION}

\section{Summary of main results}

The absence of randomized controlled trials testing music education for improving the reading skills in dyslexic children and adolescents makes it impossible to evaluate the effectiveness of music education adequately.

\section{Overall completeness and applicability of evidence}

There is a lack of high-quality evidence on which to base any decision about the implementation of music education for dyslexic children on a population level. We would encourage researchers to formally test the effectiveness of music education for children and adolescents with dyslexia, as well as considering other aspects, such as economic evaluation.

\section{Quality of the evidence}

There were no included studies.

\section{Potential biases in the review process}

We developed a sensitive search strategy that included sources of unpublished studies in order to minimize publication bias. We applied no date or language limits.

It is important to stress that the process of the study selection, conducted by two independent observers with distinct academic backgrounds (RBA, a biologist with expertise in evidence-based medicine, and HCM, a musician with expertise in design of educational trials and psychometry) was thorough.

\section{Agreements and disagreements with other studies or reviews}

We hope that the information available in this review might encourage researchers to conduct experiments about the effectiveness of music education for improving the reading skills in children with dyslexia, using the methodological rigor of a randomized controlled trial. Currently, there is no available evidence to either recommend or not recommend the use of musical education for dyslexic children, so future randomized controlled trials or cohort studies are justified. Since the studies are normally conducted in a educational context, it is important to consider the influence of covariates at the cluster level where all participants in a cluster are affected in a similar manner as result of sharing exposure to a common environment (Donner 2000).

\section{AUTHORS, CONCLUSIONS}

\section{Implications for practice}

In spite of the fact that musical education is popular and considered a beneficial intervention in the young population for the development of various cognitive skills, there is no evidence from randomized controlled trials to demonstrate potential advantages (or even disadvantages) of music education for improving reading skills, academic achievement, or self esteem in children and adolescents with dyslexia.

\section{Implications for research}

Well-designed studies with enough statistical power are needed in order to verify the effectiveness of music education for improving 
reading skills and academic achievement in dyslexic children and adolescents. Although music education in itself does not aim to improve reading skills, some studies showing a relationship between musical abilities and linguistic skills, and findings about neuroplasticity, suggest it is theoretically possible that music would help dyslexic children and adolescents.

\section{ACK NOW LEDGEMENTS}

Thanks to Geraldine Macdonald (CDPLPG Co-ordinating Editor) and Chris Champion and Laura MacDonald (CDPLPG Managing Editors) and Elaine McKay (CDPLPG Assistant Managing Editor) for hard work, patience and support of this project; to Jo Abbott and Margaret Anderson (Trial Search Co-ordinators of the CDPLPG) for searches; and to Julian Higgins for all the pertinent commentaries and suggestions during the development of this work.

\section{RE F E R E N C E S}

\section{References to studies excluded from this review}

\section{Banks 1999 \{published data only\}}

Banks A. The effects of music instruction on the visual perception of students with dyslexia or other reading problems [Thesis]. Virginia State University, 1999. [: OCLC: 50046735]

Draper 2007 \{published data only\}

Draper EADA. The effect of music, gestures, and music with gestures on the sight-word recognition of students with dyslexia [Thesis]. Florida State University, 2007. [: OCLC: 173845011]

Fiveash 1995 \{published data only\}

Fiveash D. Music as an educative enrichment medium for the remediation of children with reading problems [Thesis]. University of Cape Town, 1995. [: OCLC: 122275838]

Jaarsma 1998 \{published data only\}

Jaarsma B, Ruijssenaars A, den Broeck W. Dyslexia and learning musical notation: a pilot study. Annals of Dyslexia 1998;48(1):137-54.

Overy 2003 \{published data only\}

Overy K. Dyslexia and music - from timing deficits to musical intervention. Annals of the New York Academy of Sciences 2003;999:497-505. [PUBMED: 14681173]

Register 2007 \{published data only\}

Register D, Darrow AA, Standley J, Swedberg O. The use of music to enhance reading skills of second grade students and students with reading disabilities. Journal of Music

Therapy 2007;44(1):23-37. [PUBMED: 17419662]

\section{Additional references}

\section{Anvari 2002}

Anvari S, Trainor L, Woodside LJ, Levy BA. Relations among musical skills, phonological processing, and early reading ability in preschool children. Journal of Experimental Child Psychology 2002;83:111-30. [DOI: 10.1016/ S0022-0965(02)00124-8]

Besson 2007

Besson M, Schön D, Moreno S, Santos A, Magne C. Influence of musical expertise and musical training on pitch processing in music and language. Restorative Neurology and Neuroscience 2007;25(3-4):399-410. [PUBMED: 17943015]

Bishop 2004

Bishop DV, Snowling MJ. Developmental dyslexia and specific language impairment: same or different?. Psychological Bulletin 2004;130(6):858-86.

Blomert 2005

Blomert L. Dyslexie in Nederland. Amsterdam: Uitgeverij Nieuwezijds, 2005.

Bradley 1978

Bradley L, Bryant PE. Difficulties in auditory organisation as a possible cause of reading backwardness. Nature 1978; 271:746-7. [PUBMED: 625341]

\section{Chall 1990}

Chall JS, Jacobs VA, Baldwin LE. The Reading Crisis. Cambridge, MA: Harvard University Press, 1990.

Cheek 1999

Cheek JM, Smith LR. Music training and mathematics achievement. Adolescence 1999;34(136):759-61. [PUBMED: 1073070]

Deeks 2008

Deeks JJ, Higgins JPT, Altman DG. Chapter 9: Analysing data and undertaking meta-analyses. Higgins JPT, Green S (editors). Cochrane Handbook for Systematic Reviews of Interventions version 5.01 [updated September 2008]. The Cochrane Collaboration, 2008. Available from www.cochrane-handbook.org.

\section{Donner 1980}

Donner A, Koval JJ. The estimation of intraclass correlation in the analysis of family data. Biometrics 1980;36:19-25.

Donner 2000

Donner A, Klar N. Design and Analysis of Cluster Randomization Trials in Health Research. John Wiley \& Sons, 2000.

Douglas 1994

Douglas S, Willatts P. The relationship between musical ability and literacy skills. Journal of Research in Reading 1994;17(2):99-107. [DOI: 10.1111/ j.1467-9817.1994.tb00057.x] 
Egger 1997

Egger M, Davey Smith G, Schneider M, Minder C. Bias in meta-analysis detected by a simple graphical test. $B M J$ 1997;315:629-34.

\section{Fisher 2001}

Fisher D, McDonald N. The intersection between music and early literacy instruction: listening to literacy!. Reading Improvement 2001;38:106-16. [: EJ636907]

\section{Follmann 1992}

Follmann D, Elliott P, Suh I, Cutler J. Variance imputation for overviews of clinical trials with continuous response. Journal of Clinical Epidemiology 1992;45(7):769-73.

\section{Fuchs 1988}

Fuchs LS, Fuchs D, Maxwell L. The validity of informal reading comprehension measures. Remedial and Special Education 1988;9:20-8. [: EJ370421]

\section{Fuchs 2001}

Fuchs LS, Fuchs D, Hosp MK, Jenkins JR. Oral reading fluency as an indicator of reading competence: a theoretical, empirical, and historical analysis. Scientific Studies of Reading 2001;5(3):239-56. [: EJ640702]

\section{Gabrieli 2009}

Gabrieli JD. Dyslexia: a new synergy between education and cognitive neuroscience. Science 2009;325:280-3.

\section{Gamble 2005}

Gamble C, Hollis S. Uncertainty method on best-worst case analysis in a binary meta-analysis. Journal of Clinical Epidemiology 2005;58(6):579-88.

\section{Gold 2004}

Gold C, Voracek M, Wigram T. Effects of music therapy for children and adolescents with psychopathology: a metaanalysis. Journal of Child Psychology and Psychiatry and Allied Disciplines 2004;45(6):1054-63.

\section{Gold 2009}

Gold C, Solli HP, Krüger V, Lie SA. Dose-response relationship in music therapy for people with serious mental disorders: systematic review and meta-analysis. Clinical Psychology Review 2009;29(3):193-207.

\section{Goswami 1990}

Goswami U, Bryant P. Phonological Skills and Learning to Read. Hove, East Sussex: Psychology Press Ltd, 1990.

\section{Green 2008}

Green L. Music, Informal Learning and the School: A New Classroom Pedagogy. London: Ashgate Press, 2008.

\section{Hanes 1986}

Hanes ML. Rhythm as a factor of mediated and non mediated processing in reading. In: Evans JR, Clynes M editor(s). Rhythm in Psychological, Linguistic and Musical Processes. Springfield, IL: Charles C Thomas, 1986:99-130.

\section{Hansen 2002}

Hansen D, Bernstorf E. Linking music learning to reading instruction. Music Educators Journal 2002;88:17-21. [: EJ672219]

\section{Henry 1958}

Henry N, editor. Basic Concepts in Music Education. Chicago: University of Chicago Press, 1958.

\section{Higgins 2002}

Higgins JPT, Thompson SG. Quantifying heterogeneity in a meta-analysis. Statistics in Medicine 2002;21:1539-58.

\section{Higgins 2003}

Higgins JP, Thompson SG, Deeks JJ, Altman DG. Measuring inconsistency in meta-analyses. BMJ Clinical Research 2003;327(7414):557-60.

\section{Higgins 2008}

Higgins JPT, Green S (editors). Cochrane Handbook for Systematic Reviews of Interventions Version 5.0.1 [updated September 2008]. The Cochrane Collaboration, 2008. Available from www.cochrane-handbook.org.

\section{Ho 2003}

Ho YC, Cheung MC, Chan AS. Music training improves verbal but not visual memory: cross-sectional and longitudinal explorations in children. Neuropsychology 2003;17(3):439-50. [PUBMED: 1295951]

\section{Hoeft 2007}

Hoeft F, Meyler A, Hernandez A, Juel C, Taylor-Hill $\mathrm{H}$, Martindale JL, et al.Functional and morphometric brain dissociation between dyslexia and reading ability. Proceedings of the National Academy of Sciences of the United States of America 2007;104(10):4234-9. [PUBMED: 17360506]

\section{Hulme 2002}

Hulme C, Hatcher PJ, Nation K, Brown A, Adams J, Stuart G. Phoneme awareness is a better predictor of early reading skill than onset-rime awareness. Journal of Experimental Child Psychology 2002;82(1):2-28. [PUBMED: 12081455]

\section{Hurwitz 1975}

Hurwitz L, Wolff P, Bortnick B, Kokas K. Nonmusical effects of the Kodály music curriculum in primary grade children. Journal of Learning Disabilities 1975;8(3):167-74. [: EJ119477]

\section{Huss 2010}

Huss M, Verney JP, Fosker T, Mead N, Goswami U. Music, rhythm, rise time perception and developmental dyslexia: perception of musical meter predicts reading and phonology. Cortex 2010 Aug 5 [Epub ahead of print]. [DOI: 10.1016/ j.physletb.2003.10.071; PUBMED: 20843509]

\section{Jenkins 2003}

Jenkins JR, Fuchs LS, Van Der Broek P, Epsin C, Deno SL. Sources of individual differences in reading comprehension and reading fluency. Journal of Educational Psychology 2003; 95:719-29. [: EJ678591]

\section{Keller 1963}

Keller W. Einführung in "Musik für Kinder". 2nd Edition. Mainz: Schott, 1963.

\section{Kilgour 2000}

Kilgour AR, Jakobson LS, Cuddy LL. Music training and rate of presentation as mediators of text and song recall. Memory and Cognition 2000;28:700-10. 
Kolinsky 2009

Kolinsky R, Cuvelier H, Goetry V, Peretz I, Morais J. Music training facilitates lexical stress processing. Music Perception 2009;26(3):235-46.

Kronbichler 2008

Kronbichler M, Wimmer H, Staffen W, Hutzler F, Mair A, Ladurner G. Developmental dyslexia: gray matter abnormalities in the occipitotemporal cortex. Human Brain Mapping 2008;29(5):613-25. [: 17636558]

Kuhn 2003

Kuhn MR, Stahl SA. Fluency: a review of developmental and remedial practices. Journal of Educational Psychology 2003;95(1):3-21. [DOI: 10.1037/0022-0663.95.1.3]

\section{Latour 1997}

Latour J, Abraira V, Cabello JB, López Sánchez J. Investigation methods in clinical cardiology. IV. Clinical measurements in cardiology: validity and errors of measurements. Revista Española de Cardiología 1997;50(2): 117-28. [PUBMED: 9091999]

\section{Lefebvre 2008}

Lefebvre C, Manheimer E, Glanville J. Chapter 6: Searching for studies. Higgins JPT, Green $S$ (editors). Cochrane Handbook for Systematic Reviews of Interventions. Chichester: John Wiley \& Sons, 2008.

\section{Leinonen 2001}

Leinonen S, Muller K, Leppanen P, Aro M, Ahonen T, Lyytinen $\mathrm{H}$. Heterogeneity in adult dyslexic readers: relating processing skills to the speed and accuracy of oral text reading. Reading and Writing: An Interdisciplinary Journal 2001;14:265-96. [: EJ629161]

\section{Lyon 1996}

Lyon GR. Learning disabilities. Future Child 1996;6(1): 54-76. [: 8689262]

Lyon 2003

Lyon GR, Shaywitz SE, Shaywitz BA. Defining dyslexia, comorbidity, teachers' knowledge of language and reading: a definition of dyslexia. Annals of Dyslexia 2003;53(1): 1-14. [DOI: 10.1007/s11881-003-0001-9]

Magne 2006

Magne C, Schön D, Besson M. Musician children detect pitch violations in both music and language better than nonmusician children: behavioral and electrophysiological approaches. Journal of Cognitive Neuroscience 2006;18(2): 199-211. [PUBMED: 16494681]

\section{Marques 2007}

Marques C, Moreno S, Castro SL, Besson M. Musicians detect pitch violation in a foreign language better than nonmusicians: behavioral and electrophysiological evidence. Journal of Cognitive Neuroscience 2007;19(9):1453-63. [PUBMED: 17714007]

\section{Martin 1986}

Martin JG. Aspects of rhythmic structure in speech perception. In: Evans JR, Clynes M editor(s). Rhythm in Psychological, Linguistic \& Musical Processes. Springfield, IL: Charles C Thomas, 1986:79-98.
Mills 1973

Mills E, Murthy T. The Suzuki Conception: An Introduction to a Successful Method for Early Music Education. Berkeley: Diablo, 1973.

\section{Moreno 2009}

Moreno S, Marques C, Santos A, Santos M, Castro SL, Besson M. Musical training influences linguistic abilities in 8-year-old children: more evidence for brain plasticity. Cerebral Cortex 2009;19(3):712-23.

\section{Muter 2004}

Muter V, Hulme C, Snowling MJ, Stevenson J. Phonemes, rimes, vocabulary, and grammatical skills as foundations of early reading development: evidence from a longitudinal study. Developmental Psychology 2004;40(5):665-81.

[PUBMED: 15355157]

\section{NAfME 2011}

National Association for Music Education. National Standards for Music Education. http://musiced.nafme.org/ resources/national-standards-for-music-education/ 2011 (accessed 30 January 2012).

\section{National Reading Panel 2000}

Report of the National Reading Panel. Teaching children to read: an evidence-based assessment of the scientific research literature on reading and its implications for reading instruction. National Reading Panel. Washington, DC: Government Printing Office, 2000.

\section{Nikjeh 2009}

Nikjeh DA, Lister JJ, Frisch SA. Preattentive corticalevoked responses to pure tones, harmonic tones, and speech: influence of music training. Ear and Hearing 2009;30(4): 432-46. [PUBMED: 19494778]

\section{Overy 2000}

Overy K. Dyslexia, temporal processing and music: the potential of music as an early learning aid for dyslexic children. Psychology of Music 2000;28:218-29.

\section{Patel 1998}

Patel A, Gibson E, Ratner J, Besson M, Holcomb PJ. Processing syntactic relations in language and music: an event-related potential study. Journal of Cognitive Neuroscience 1998;10:717-33.

\section{Patel 2008}

Patel AD. Music, Language and the Brain. Oxford: Oxford University Press, 2008.

\section{Pennington 1996}

Pennington BF, Gilger JW. How is dyslexia transmitted? . In: Chase $\mathrm{CH}$, Roen GD, Sherman GF editor(s). Developmental Dyslexia: Neural, Cognitive and Genetic Mechanisms. Baltimore, MD: York Press, 1996:41-61.

\section{Pernet 2009}

Pernet C, Andersson J, Paulesu E, Demonet JF. When all hypotheses are right: a multifocal account of dyslexia. Human Brain Mapping 2009;30(7):2278-92. [PUBMED: 1923587] 


\section{Pinnell 1995}

Pinnell GS, Pikulski JJ, Wixon KK, Campbell JR, Gough PB, Beatty AS. Listening to children read aloud. National Center for Education Statistics 1995; Vol. 1, issue 1.

\section{Ramus 2003}

Ramus F. Developmental dyslexia: specific phonological deficit or general sensorimotor dysfunction?. Current Opinion in Neurobiology 2003;13:212-8.

\section{RevMan 2008}

The Nordic Cochrane Centre, The Cochrane Collaboration. Review Manager (RevMan). 5.0. Copenhagen: The Nordic Cochrane Centre, The Cochrane Collaboration, 2008.

\section{Schellenberg 2004}

Schellenberg EG. Music lessons enhance IQ. Psychological Science 2004;15(8):511-4. [PUBMED: 15270994]

\section{Schlaug 2005}

Schlaug G, Norton A, Overy K, Winner E. Effects of music training on the child's brain and cognitive development. Annals of the New York Academy of Sciences 2005;1060: 219-30. [PUBMED: 16597769]

\section{Schön 2004}

Schön D, Magne C, Besson M. The music of speech: music training facilitates pitch processing in both music and language. Psychophysiology 2004;41(3):341-9. [PUBMED: 15102118]

\section{Semel 1986}

Semel E, Wiig EH, Secord W. Clinical Evaluation of Language Fundamentals - Revised. San Antonio, Texas: The Psychological Corporation, 1986.

\section{Shaywitz 1998}

Shaywitz SE. Dyslexia. New England Journal of Medicine 1998;338:307-12.

\section{Shaywitz 2003}

Shaywitz S. Overcoming Dyslexia - A New and Complete Science-Based Program for Reading Problems at any Level. New York: Knopf, 2003.

\section{Sloboda 1985}

Sloboda J. The Musical Mind: The Cognitive Psychology of Music. Oxford: Clarendon Press, 1985.

\section{Snowling 1996}

Snowling M, Stothard S, McLean J. Graded Nonword Reading Test. Bury St Edmunds, England: Thames Valley Test Publishers, 1996.

\section{Stanovich 1986}

Stanovich KE. Matthew-effects in reading: some consequences of individual differences in the acquisition of literacy. Reading Research Quarterly 1986;21:360-407.

\section{Sutton 1995}

Sutton J. The sound-world of speech- and languageimpaired children: the story of a current music therapy research project. In: Gilroy AL editor(s). Art and Music: Therapy and Research. London: Routledge, 1995:153-63.

\section{Sándor 1975}

Sándor F (editor). Music Education in Hungary. 3rd Edition. Boosey \& Hawkes, 1975.

Ukoumunne 1999 Ukoumunne OC, Gulliford MC, Chinn S, Sterne JA, Burney PG. Methods for evaluating area-wide and organisation based interventions in health and health care: a systematic review. Health Technology Assessment 1999;3(5): iii-92.

\section{Wagner 1987}

Wagner RK, Torgesen JK. The nature of phonological processing and its causal role in the acquisition of reading skills. Psychological Bulletin 1987;101:192-212.

\section{Wagner 1999}

Wagner RK, Torgesen JK, Rashotte CA. The Comprehensive Test of Phonological Processing. Austin: PRO-ED, 1999.

\section{Wolf 2005}

Wolf M, Denckla MB. RAN/RAS: Rapid Automatized Naming and Rapid Alternating Stimulus Tests. Austin: PROED, 2005.

\section{Woodcock 1987}

Woodcock RW. Woodcock Reading Mastery Tests - Revised Examiner's Manual. Circle Pines: American Guidance Services, 1987.

\section{Zoccolotti 2010}

Zoccolotti P, Friedmann N. From dyslexia to dyslexias, from dysgraphia to dysgraphias, from a cause to causes: a look at current research on developmental dyslexia and dysgraphia. Cortex 2010;46:1211-5. [: 20933228]

* Indicates the major publication for the study 


\section{CHARACTERISTICS OF STUDIES}

\section{Characteristics of excluded studies [ordered by study ID]}

\begin{tabular}{|c|c|}
\hline Study & Reason for exclusion \\
\hline Banks 1999 & The main outcome is related to visual perception of children with dyslexia \\
\hline Draper 2007 & $\begin{array}{l}6 \text { dyslexic children from a private school received instruction on target sight-words using music, gestures, and music } \\
\text { with gestures. No control group }\end{array}$ \\
\hline Fiveash 1995 & Not a clinical trial, but a theoretical discussion about how music could help children with reading disabilities \\
\hline Jaarsma 1998 & $\begin{array}{l}\text { No reading outcome. Measured effects of a new intervention for learning musical notation in students with dyslexia; } \\
\text { therefore, the main outcome was learning musical notation }\end{array}$ \\
\hline Overy 2003 & There was no control group \\
\hline Register 2007 & Heterogeneity in the sampling (children without reading disabilities together children with) and no randomization \\
\hline
\end{tabular}




\section{DATA ANDANALYSES}

This review has no analyses.

\section{A P P E N D I C E S}

\section{Appendix I. Search strategies}

CENTRAL, part of The Cochrane Library

\#1 MeSH descriptor Music, this term only

\#2 MeSH descriptor Music Therapy, this term only

\#3 music* $^{*}$

\#4 MeSH descriptor Pitch Perception explode all trees

\#5 pitch*

\#6 rhythm*

\#7 harmon*

\#8 timbre*

\#9 (sing or singing or song* or choral or choir* or orchestra*)

\#10 dalcroze*

\#11 kodaly*

\#12 ((orff* or suzuki*) NEAR/3 (method* or approach* or system* or technique*))

\#13 MeSH descriptor Time Perception, this term only

\#14 MeSH descriptor Percussion, this term only

\#15 percussion

\#16 (\#1 OR \#2 OR \#3 OR \#4 OR \#5 OR \#6 OR \#7 OR \#8 OR \#9 OR \#10 OR \#11 OR \#12 OR \#13 OR \#14 OR \#15)

$\# 17 \mathrm{MeSH}$ descriptor Dyslexia explode tree 3

\#18 dyslexi*

\#19 MeSH descriptor Reading, this term only

\#20 (reading* near/3 (comprehension or disorder* or disabilit* or problem* or difficult* or deficien* or fluenc*))

\#21 (word or text) NEXT blind*

$\# 22$ alexia

\#23 (\#17 OR \#18 OR \#19 OR \#20 OR \#21 OR \#22)

\#24 (\#16 AND \#23)

\section{Ovid MEDLINE(R)}

1 Musicl

2 Music Therapy/

3 music\$.tw.

4 Pitch Perception/

5 Pitch Discrimination/

6 pitch.tw.

7 rhythm\$.tw.

8 harmon\$.tw.

9 (melody or melodies).tw.

10 timbre.tw.

11 (sing or singing or song $\$$ or choral or choir $\$$ or orchestra $\$$ ).tw.

12 dalcroze $\$$.tw.

13 kodaly\$.tw.

14 time perception/

Music education for improving reading skills in children and adolescents with dyslexia (Review)

Copyright $\odot 2012$ The Cochrane Collaboration. Published by John Wiley \& Sons, Ltd. 
15 ((orff\$ or suzuki\$) adj3 (method\$ or approach\$ or system\$ or technique\$)).tw.

16 Percussion/

17 percussion.tw.

18 exp Dyslexia/

19 dyslexi\$.tw.

20 reading/

21 (reading $\$$ adj3 (comprehension or disorder\$ or disabilit\$ or problem\$ or difficult $\$$ or deficien $\$$ or fluenc\$)).tw.

22 ((word or text) adj blind\$).tw.

23 alexia.tw.

24 or/ $18-23$

25 or/ $1-17$

2624 and 25

27 randomized controlled trial.pt.

28 controlled clinical trial.pt.

29 randomi\#ed.ab.

30 placebo\$.ab.

31 drug therapy.fs.

32 randomly.ab.

33 trial.ab.

34 groups.ab.

35 or/27-34

36 exp animals/ not humans.sh.

3735 not 36

3826 and 37

\section{Ovid EMBASE}

1 exp musicl

2 music therapy/

3 music\$.tw.

4 pitch.tw.

5 rhythm/

6 rhythm $\$$.tw.

7 harmon\$.tw.

8 (melody or melodies).tw.

9 timbre.tw.

10 (sing or singing or song $\$$ or choral or choir or orchestra).tw.

11 dalcroze\$.tw.

12 kodaly\$.tw.

13 time perception/

14 ((orff\$ or suzuki\$) adj3 (method\$ or approach\$ or system $\$$ or technique $\$))$.tw.

15 percussion/

16 percussion.tw.

17 or/1-16

18 dyslexia/

19 alexia/

20 dyslexi\$.tw.

21 alexia.tw.

22 reading/

23 (reading $\$$ adj3 (comprehension or disorder\$ or disabilit\$ or problem\$ or difficult $\$$ or deficien\$ or fluenc\$)).tw.

24 ((word or text) adj blind\$).tw.

25 or/ $18-24$

2617 and 25

27 exp Clinical trial/

Music education for improving reading skills in children and adolescents with dyslexia (Review)

Copyright $\odot 2012$ The Cochrane Collaboration. Published by John Wiley \& Sons, Ltd. 
28 Randomized controlled trial/

29 Randomization/

30 Single blind procedure/

31 Double blind procedure/

32 Crossover procedure/

33 Placebo/

34 Randomi\#ed.tw.

35 RCT.tw.

36 (random\$ adj3 (allocat\$ or assign\$)).tw.

37 randomly.ab.

38 groups.ab.

39 trial.ab.

40 ((singl\$ or doubl\$ or trebl\$ or tripl\$) adj3 (blind\$ or mask\$)).tw.

41 Placebo\$.tw.

42 Prospective study/

43 (crossover or cross-over).tw.

44 prospective.tw.

45 treatment outcome/

46 comparative study/

47 ((evaluat\$ or compar\$) adj3 (research or study or studies)).tw.

48 ((therap\$ or treatment\$) adj3 (evaluat\$ or outcome\$ or compar\$)).tw.

49 or $/ 27-48$

5026 and 49

\section{CINAHL Plus (EBSCOhost)}

S42 S23 and S41

S41 S24 or S25 or S26 or S27 or S28 or S29 or S30 or S31 or S32 or S33 or S34 or S35 or S36 or S37 or S38 or S39 or S40

S40 (MH "Evaluation Research”) OR (MH “Summative Evaluation Research”) OR (MH "Program Evaluation”)

S39 (MH “Treatment Outcomes”) S38 (MH “Comparative Studies”)

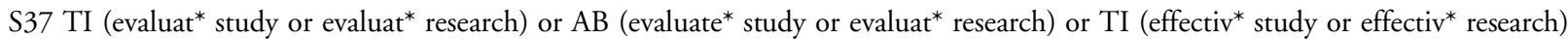
or AB (effectiv* study or effectiv* research) OR TI (prospectiv* study or prospectiv* research) or AB(prospectiv* study or prospectiv* research) or TI (follow-up study or follow-up research) or AB (prospectiv* study or prospectiv* research)

S36 "cross over*"

S35 crossover*

S34 (MH "Crossover Design")

S33 (tripl* N3 mask*) or (tripl* N3 blind*)

S32 (trebl* N3 mask*) or (trebl* N3 blind ${ }^{*}$ )

S31 (doubl* N3 mask*) or (doubl* N3 blind*)

S30 (singl* N3 mask*) or (singl* N3 blind*)

S29 (clinic $^{*} \mathrm{~N} 3$ trial $^{*}$ ) or (control* N3 trial $^{*}$ )

S28 (random* N3 allocat*) or (random* N3 assign*)

S27 randomis* or randomiz*

S26 (MH "Meta Analysis")

S25 (MH "Clinical Trials+")

S24 MH random assignment

S23 S14 and S22

S22 S15 or S16 or S17 or S18 or S19 or S20 or S21

S21 (word blind*) or (text blind*)

S20 (reading* $\mathrm{n} 3$ comprehension) or (reading* N3 disorder*) or (reading* N3

disabilit*) or (reading* ${ }^{*}$ 3 problem*) or (reading* N3 difficult*) or

(reading* N3 deficien*) or (reading* N3 fluenc*)

S19 (MH "Reading Disorders")

S18 (MH "Readability") OR (MH “Reading+")

Music education for improving reading skills in children and adolescents with dyslexia (Review)

Copyright ( 2012 The Cochrane Collaboration. Published by John Wiley \& Sons, Ltd. 
S17 alexia

S16 dyslexi*

S15 (MH "Dyslexia+")

S14 S1 or S2 or S3 or S4 or S5 or S6 or S7 or S8 or S9 or S10 or S11 or S12 or S13

S13 percussion*

S12 (MH "Percussion")

S11 dalcroze* or kodaly* or orff* or suzuki*

S10 (sing or singing or song* or choral or choir or orchestra*)

S9 timbre

S8 melody or melodies

S7 harmon*

S6 rhythm*

S5 pitch* $^{*}$

S4 (MH "Pitch Perception")

S3 music*

S2 (MH "Music Therapy")

S1 (MH "Music")

\section{PsycINFO search strategies}

PsycINFO moved to different supplier during the course of the review so when the searches were updated 2012, the PsycINFO strategy was adapted for the new platform (OVID).

\section{PsycINFO (EBSCOhost)}

S43 S28 and S42

S42 S29 or S30 or S31 or S32 or S33 or S34 or S35 or S36 or S37 or S38 or S39 or S40 or S41

S41 (evaluation N3 stud* or evaluation N3 research*)

S40 (effectiveness N3 stud* or effectiveness N3 research*)

S39 DE "Placebo" or DE "Evaluation" or DE "Program Evaluation" OR DE

"Educational Program Evaluation" OR DE "Mental Health Program Evaluation"

OR DE "Treatment effectiveness evaluation"

S38 (DE "Random Sampling” or DE “Clinical Trials") or (DE "Experiment

Controls")

S37 "cross over*"

S36 crossover*

S35 (tripl* N3 mask*) or (tripl* N3 blind*)

S34 (trebl* N3 mask ${ }^{*}$ ) or (trebl* N3 blind*)

S33 (doubl* N3 mask*) or (doubl* N3 blind*)

S32 (singl ${ }^{*} \mathrm{~N} 3$ mask $\left.^{*}\right)$ or $\left(\right.$ singl $^{*} \mathrm{~N} 3$ blind $\left.^{*}\right)$

S31 (clinic* $^{*}$ N3 trial $^{*}$ ) or (control* N3 trial ${ }^{*}$ )

S30 (random* N3 allocat*) or (random* N3 assign*)

S29 randomis* or randomiz*

S28 S19 and S27

S27 S20 or S21 or S22 or S23 or S24 or S25 or S26

S26 (word blind*) or (text blind*)

S25 (reading* $\mathrm{n} 3$ comprehension) or (reading* N3 disorder*) or (reading* N3

disabilit*) or (reading* N3 problem*) or (reading* N3 difficult*) or

(reading* N3 deficien ${ }^{*}$ ) or (reading* N3 fluenc*)

S24 alexia

S23 dyslexi*

S22 DE "Reading Ability" OR DE "Reading Achievement" OR DE "Reading

Comprehension” OR DE "Reading Development" OR DE "Reading Education” OR DE

"Reading Skills" OR DE "Reading Speed"

S21 DE “Reading” OR DE “Oral Reading” OR DE “Remedial Reading” OR DE

"Silent Reading"

S20 DE "Dyslexia” OR DE “Alexia” OR DE "Reading Disabilities"

Music education for improving reading skills in children and adolescents with dyslexia (Review)

Copyright $\odot 2012$ The Cochrane Collaboration. Published by John Wiley \& Sons, Ltd. 
S19 S1 or S2 or S3 or S4 or S5 or S6 or S7 or S8 or S9 or S10 or S11 or S12 or S13 or S14 or S15 or S16 or S17 or S18

S17 dalcroze* or kodaly* or orff* or suzuki*

S16 (sing or singing or song* or choral or choir* or orchestra*)

S15 timbre

S14 melod*

S13 harmon*

S12 rhythm*

S11 pitch*

S10 music*

S9 DE "Pitch Perception" OR DE "Pitch Discrimination"

S8 DE “Tempo"

S7 DE "Singing"

S6 DE "Music Perception"

S5 DE "Musicians"

S4 DE "Musical Ability"

S3 DE "Music Therapy"

S2 DE "Music Education"

S1 DE "Music" OR DE "Musical Instruments" OR DE "Rock Music"

PsycINFO (OVID)

1 exp musicl

2 music education/

3 music therapy/

4 musical ability/

5 musicians/

6 music perception/

7 singing/

8 tempo/

9 pitch perception/

10 (music\$ or pitch\$ or rhythm\$ or harmon $\$$ or $\operatorname{melod} \$$ or timbre).tw.

11 (dalcroze\$ or kodaly\$ or orff\$ or suzuki\$).tw.

12 (sing or singing or song $\$$ or choral $\$$ or choir $\$$ or orchestra $\$$ or percussion $\$$ ).tw.

13 or/1-12

14 dyslexia/

15 alexia/

16 reading disabilities/

17 reading/ or oral reading/ or remedial reading/ or silent reading/

18 reading ability/ or reading achievement/ or reading comprehension/ or reading development/ or reading education/ or exp reading skills/ or reading speed/ or sight vocabulary/

19 dyslexi\$.tw.

20 alexia\$.tw.

21 (reading $\$$ adj3 (comprehension or disorder\$ or disabilit\$ or problem\$ or difficult\$ or deficien\$ or fluenc\$)).tw.

22 ((word or text) adj blind $\$)$.tw.

23 or/14-22

24 clinical trials/

25 (randomis* or randomiz*).tw.

26 (random\$ adj3 (allocat\$ or assign\$)).tw.

27 ((clinic\$ or control\$) adj trial\$).tw.

28 ((singl\$ or doubl\$ or trebl\$ or tripl\$) adj3 (blind\$ or mask\$)).tw.

29 (crossover\$ or "cross over\$").tw.

30 random sampling/

31 Experiment Controls/

32 Placebo/

33 placebo\$.tw.

Music education for improving reading skills in children and adolescents with dyslexia (Review)

Copyright $\odot 2012$ The Cochrane Collaboration. Published by John Wiley \& Sons, Ltd. 
34 exp program evaluation/

35 treatment effectiveness evaluation/

36 ((effectiveness or evaluat\$) adj3 (stud\$ or research\$)).tw.

37 or/24-36

3813 and 23 and 37

ERIC search strategies

ERIC moved to different supplier during the course of the review so when the searches were updated 2012, the ERIC strategy was adapted for the new platform (ProQuest).

ERIC (Dialog Datastar) used for 2011 searches

“(((Music\#.W..DE.) OR (MUSIC-EDUCATION.DE. OR MUSIC-TEACHERS.DE. OR MUSICAL-INSTRUMENTS.DE. OR MUSIC-ACTIVITIES.DE. OR MUSICIANS.W..DE. OR SINGING.W..DE. OR MUSICAL-COMPOSITION.DE.) OR (MUSIC-THERAPY.DE.) OR (music\$.TI,AB.) OR (( sing OR singing ) .TI,AB.) OR (( sing OR singing OR song\$1 OR choral OR choir\$1 OR orchestra $\$ 1$ ) .TI,AB.) OR (pitch\$.TI,AB.) OR (rhythm\$.TI,AB.) OR (harmon\$.TI,AB.) OR (melod\$.TI,AB.) OR (timbre.TI,AB.) OR (( dalcroze\$ OR kodaly\$ ) .TI,AB.) OR (( orff\$ OR suzuki\$ ) .TI,AB.) OR (percussion.TI,AB.) OR (Music-Techniques.DE.)) AND ((Reading\#.W..DE.) OR (READING-FLUENCY.DE. OR READING-COMPREHENSION.DE. OR READING-SKILLS.DE. OR READING-DIFFICULTIES.DE. OR READING-RATE.DE. OR READING-IMPROVEMENT.DE.) OR (Dyslexia.W..DE.) OR (alexia.TI,AB.) OR (READING-INSTRUCTION.DE.) OR (( reading\$ NEAR ( comprehension OR disorder\$ OR disabilit\$ OR problem\$ OR difficult\$ OR deficien\$ OR fluenc\$ ) ) .TI,AB.) OR (( ( word OR text ) ADJ blind\$ ) .TI,AB.) OR (dyslexi\$.TI,AB.))) AND ((CONTROL-GROUPS.DE.) OR (EXPERIMENTAL-GROUPS.DE.) OR (LONGITUDINAL-STUDIES.DE.) OR (FOLLOW-UP-STUDIES.DE.) OR (PROGRAM-EFFECTIVENESS.DE.) OR (( ( PROSPECTIVE OR FOLLOW ADJ UP OR EVALUAT\$4 OR COMPAR \$4 OR BLIND\$2 ) NEAR ( STUDY OR STUDIES ) ) .TI,AB.) OR (( EVALUAT\$4 NEAR RESEARCH ) .TI,AB.) OR (( ( COMPAR\$4 OR CONTROL\$1 ) NEAR GROUP\$1 ) .TI,AB.) OR (RANDOM\$.TI,AB.) OR (INTERVENTION\$1.TI,AB.) OR (EXPERIMENT\$2.TI,AB.) OR (TRIAL\$1.TI,AB.) OR (COMPARATIVE-ANALYSIS.DE.))" ERIC (ProQuest) used for 2012 searches

(SU.EXACT(“Individualized Reading”) OR SU.EXACT(“Reading”) OR SU.EXACT("Recreational Reading”) OR SU.EXACT(“Sustained Silent Reading”) OR SU.EXACT(“Independent Reading”) OR SU.EXACT(“Beginning Reading”) OR SU.EXACT(“Story Reading”) OR SU.EXACT(“Basal Reading”) OR SU.EXACT(“Functional Reading”) OR SU.EXACT(“Directed Reading Activity”) OR SU.EXACT(“Oral Reading”) OR SU.EXACT(“Silent Reading”) OR SU.EXACT(“Corrective Reading”) OR SU.EXACT(“Music Reading”) OR SU.EXACT(“Early Reading”) OR SU.EXACT(“Content Area Reading”) OR SU.EXACT(“Speed Reading”) OR SU.EXACT(“Remedial Reading”) OR SU.EXACT(“Critical Reading”) OR SU.EXACT(“Reading Fluency”) OR SU.EXACT(“Reading Rate”) OR SU.EXACT(“Reading Skills”) OR SU.EXACT(“Reading Achievement”) OR SU.EXACT(“Reading Improvement”) OR SU.EXACT(“Reading Comprehension”) OR (reading* NEAR/5 (comprehension OR disorder* OR disabilit* OR problem* OR difficult* OR deficien* OR fluenc*)) OR (word blind*) OR (text blind*) OR SU.EXACT("Dyslexia”) OR (alexia OR Dyslex*)) AND ((SU.EXACT(“Musical Composition”) OR SU.EXACT(“Music Teachers”) OR SU.EXACT("Music Education”) OR SU.EXACT(“Music”) OR SU.EXACT(“Musicians”) OR SU.EXACT(“Musical Instruments”) OR SU.EXACT(“Music Techniques”) OR SU.EXACT(“Singing”) OR SU.EXACT(“Music Therapy”) OR SU.EXACT(“Music Activities”) OR (music* OR sing OR singing OR song* OR choral OR choir* OR orchestra) OR (pitch OR rhythm* OR harmon* OR melod* OR timbre OR percussion) OR (dalcroze* OR kodaly* OR orff* OR suzuki*)) AND (SU.EXACT(“Longitudinal Studies”) OR SU.EXACT(“Control Groups”) OR SU.EXACT(“Program Effectiveness”) OR SU.EXACT(“Experimental Groups”) OR SU.EXACT(“Followup Studies”) OR SU.EXACT(“Comparative Analysis”) OR prospective OR "follow up” OR ((evaluat* OR compar* OR blind*) NEAR/5 (study OR studies OR research)) OR ((compar* OR control*) NEAR/5 group*) OR random* OR intervention* OR experiment* OR trial $\left.^{*}\right)$ Databases:ERIC

\section{LILACS (Virtual Health Library)}

(read or reading or "word blindness" or dyslexic or dyslexia or alexia) and (music* or dalcroze or suzuki or orff or kodaly or percussion or harmon* or melody or melodies or pitch* or rhythm* or timbre)

Arts and Humanities Citation Index (A\&HCI), Social Science Citation Index (SSCI) and Conference Proceedings Citation Index - Social Sciences and Humanities (CPCI-SSH) (Web of Knowledge)

Topic $=\left(\right.$ music* $^{*}$ or melod* or harmon* or pitch or rhythm* or timbre or sing* or song* ${ }^{*}$ or choir* or choral ${ }^{*}$ or orchestra* or percussion* or dalcro* ${ }^{*}$ or kodaly* or orff* or suzuki*) AND Topic $=($ dyslexi* or alexia or reading disabil* or reading comprehens* or reading fluenc* ${ }^{*}$ or reading difficult* or reading deficien*) AND Topic $=\left(\right.$ random* $^{*}$ or control* ${ }^{*}$ or trial* or evaluat* ${ }^{*}$ or effectiveness or compar* ${ }^{*}$ experiment* or treatment* or program* or intervention*)

Music education for improving reading skills in children and adolescents with dyslexia (Review)

Copyright (c) 2012 The Cochrane Collaboration. Published by John Wiley \& Sons, Ltd. 
WHO ICTRP (www.who.int/ictrp/en/)

(dyslexic or dyslexia or reading ) and music*

WorldCat (www.worldcat.org)

KW: dyslexi* AND music* Limited to theses

\section{Appendix 2. Table of unused methods}

Data extraction and management
Two review authors (HCM and RBA) will independently extract data from studies that meet the inclusion criteria, using a standard extraction form Details to be extracted will include:

1. Study: information regarding the author(s); year of publication; source; country; and language

2. Characteristics of setting and participants: eligibility criteria for participants; explanation of recruitment procedures; setting (country, location, clinical or non-clinical); demographic features of the sample

3. Sampling: sample sizes for treatment and control; whether power analysis was used to determine sample size; allocation to treatment and control; explanation of method used to generate the allocation

4. Research design: type of design including major features such as random selection, random assignment, and non-equivalent control group

5. Intervention data: nature of interventions; for example, intervention focused on a specific musical instrument or methodological approach (for example, Dalcroze, Suzuki, Kodály, or Orff Method)

6. Outcome data: primary and secondary outcomes; measures used; information on reliability and validity of measures

7. Results: attrition at post intervention and follow-up; number excluded from the analysis; length of follow-up; statistical methods; type of data effect size is based on; data needed for effect size calculations

We will not be blind to the names of the study authors, institutions or journal of publication. We will resolve all disagreements by consensus amongst ourselves and referral to the editorial base of the Cochrane Developmental, Psychosocial and Learning Problems Group for arbitration when necessary

Assessment of risk of bias in included studies

At least two review authors will independently assess risk of bias within each included study in accordance with guidance in the Cochrane Handbook for Systematic Reviews of Interventions (Higgins 2008). Review authors will independently assess the risk of bias within each included study in the following domains with ratings of low risk of bias, high risk of bias, and unclear risk of bias

\section{Sequence generation}

We will describe in detail the method used to generate the allocation sequence so as to assess whether it should have produced comparable groups, and make a judgment on whether the allocation concealment sequence was adequately generated

\section{Allocation concealment}

We will describe the method used to conceal allocation sequence in sufficient detail to assess whether intervention schedules could have been foreseen 
in advance of, or during, recruitment, and make a judgment on whether allocation was adequately concealed

\section{Blinding}

We will describe any measures used to blind participants, personnel, and outcome assessors so as to assess the knowledge of any group as to which intervention a given participant might have received, and make a judgment on whether knowledge of the allocated intervention was adequately prevented during the study. Blinding in the case of the participants (for example, children), in practice, is not possible, because of nature of the intervention. The children will know whether they are receiving music education or not (compared to non-musical activity such as a control group would take part in)

\section{Incomplete outcome data}

If studies do not report intention-to-treat analyses, we will try to obtain missing data by contacting the study authors. We will extract and report data on attrition and exclusions as well as the numbers involved (compared with total randomized), reasons for attrition or exclusion where reported or obtained from investigators, and any re-inclusions in analyses performed by review authors; we will then make a judgment on whether incomplete data were dealt with adequately by the study authors. (See also Dealing with missing data).

\section{Selective outcome reporting}

We will try to assess the possibility of selective outcome reporting by investigators and judge whether reports of the study are free of any suggestion of selective outcome reporting

Validity and reliability of outcome measures used

We will assess whether the outcome measures were standardized and validated for the population

\section{Other sources of bias}

We will assess whether the study is apparently free of other problems that could put it at a high risk of bias
If participants, interventions, and outcome measures are sufficiently similar, we will carry out meta-analyses. We will enter data into an Excel spreadsheet and two authors will independently enter data into Review Manager 5 ( RevMan 2008), each author entering data from another author's extraction sheets, using the double data entry facility in Review Manager 5. Where the same rating scale has been used for all studies, we will pool data using mean differences; where different rating scales have been used to measure the same outcome, we will use standardized mean differences
Unit of analysis issues
We will follow the guidance on statistical methods for cluster-randomized trials described in the Cochrane Handbook for Systematic Reviews of Interventions (Higgins 2008, Section 16.3). We will seek direct estimates of the effect (for example, an odds ratio with its confidence interval (CI)) from an analysis that properly accounts for the cluster design; alternatively, we will extract or calculate effect estimates and their standard errors as for a parallel group trial, and adjust the standard errors to account for the clustering ( Donner 1980). This requires information on an intraclass correlation co- 
efficient (ICC), which describes the relative variability in outcome within and between clusters (Donner 1980). We will extract this information from the articles if available, and otherwise we will contact the authors or use external estimates obtained from similar studies. We will find closest-matching scenarios (with regard to both outcome measures and types of clusters) from existing databases of ICCs (Ukoumunne 1999), and if we are unable to identify any, we will perform sensitivity analyses using a high ICC of 0 . 1 , a moderate ICC of 0.01 , and a small ICC of 0.001 . We recognize that these values are relatively arbitrary, but prefer to use them to adjust the effect estimates and their standard errors due to the implausibility that the ICC is actually 0 . Subsequently, we will combine the estimates and their corrected standard errors from the cluster-randomized trials with those from parallel designs using the generic inverse variance method in Review Manager 5

Dealing with missing data

We will contact the original investigators to request any missing data and information, in order to decide whether or not missing data can be assumed to be 'missing at random'. For dichotomous data, we will report missing data and dropouts for each included study and will report the number of participants who are included in the final analysis as a proportion of all participants in each study. We will provide reasons for missing data in the narrative summary and will assess the extent to which the results of the review could be altered by the missing data by, for example, a sensitivity analysis based on consideration of 'best-case' and 'worst-case' scenarios (Gamble 2005). Here, the 'best-case' scenario is that where all participants with missing outcomes in the experimental condition had good outcomes, and all those with missing outcomes in the control condition had poor outcomes, and the 'worstcase' scenario is the converse (Higgins 2008, section 16.2.2).

For missing continuous data, we will provide a qualitative summary. The standard deviations of the outcome measures should be reported for each group in each trial. If these are not given, we will impute standard deviations using relevant data (for example, standard deviations or correlation coefficients) from other, similar studies (Follmann 1992), but only if we decide, after seeking statistical advice, that to do so is practical and appropriate

Assessment of heterogeneity

We will assess the extent of heterogeneity using the three methods suggested by the Cochrane Handbook for Systematic Reviews of Interventions (Deeks 2008): visual inspection of forest plots, the $\mathrm{Chi}^{2}$ test (increasing the level of significance to 0.10 to avoid underestimating heterogeneity) and using the $\mathrm{I}^{2}$ statistic designed to assess the impact of heterogeneity on the metaanalysis. It describes the "percentage of the variability in effect estimates that is due to heterogeneity rather than sampling error (chance)" (Higgins 2002; Higgins 2003). However, it is advised that the thresholds of the $\mathrm{I}^{2}$ statistic might be misleading and the following guide is offered:

$0 \%$ to $40 \%$ : may not be important;

$30 \%$ to $60 \%$ : may represent moderate heterogeneity;

$50 \%$ to $90 \%$ : may represent substantial heterogeneity;

$75 \%$ to $100 \%$ : considerable heterogeneity.

We will bear in mind that the importance of the observed value of $\mathrm{I}^{2}$ depends on (i) magnitude and direction of effects and (ii) strength of evidence for 

interval (CI) for $\mathrm{I}^{2}$ (Higgins 2008)).

Assessment of reporting biases

Data synthesis
We will draw funnel plots (effect size versus standard error) to assess publication bias if sufficient studies are found. Asymmetry of the plots may indicate publication bias, although they may also represent a true relationship between trial size and effect size. If we identify such a relationship, we will further examine the clinical diversity of the studies as a possible explanation (Egger 1997).

We may conduct meta-analyses to combine comparable outcome measures across studies. In any meta-analysis, the weight given to each study will be the inverse of the variance so that the more precise estimates (from larger studies with more events) are given more weight. We will use random-effects models because studies may include somewhat different treatments or populations. We will group outcome measures by length of follow-up

Subgroup analysis and investigation of heterogeneity

We are planning to carry out subgroup analyses to explore the possible differential effect of the intervention depending on the following

1. Duration of musical training: short-term (up to six months); mediumterm (between six and 12 months) and long-term (more than 12 months) 2. Type of musical training (for example, Dalcroze Method, Suzuki Method, or even a specific instrumental practice such as keyboard or string) 3. Age range of the participants (for example, children (six to 12 years) versus adolescents (13 to 18 years))

Sensitivity analysis

We will conduct the following sensitivity analyses.

1. The removal of studies with inconsistencies in the definition, measurement, or reporting of results (for example, if the number of participants varies in the report or if measures were not taken at consistent time points for all participants)

2. Changing the way that values are imputed for missing data (for example, last value carried forward versus mean scores for missing values)

3. Reanalyzing the data using different statistical approaches (for example, using a fixed-effect model instead of a random-effects model) (Higgins 2008).

\section{Appendix 3. Criteria for initial selection phase}

1. Primary studies (excluding narrative reviews, guidelines, consensus, letters, etc).

2. Studies in which the authors had offered any approach based on music education.

3. In patients with dyslexia/reading disorders (not including studies for any other clinical condition that is not strictly characterized as reading disorder or dyslexia; for example, deficit in spelling, problems in phonological awareness).

4. Irrespective of study design (prospective, retrospective, randomized controlled trials, case series, case report, etc). 


\section{H I S T O R Y}

Protocol first published: Issue 5, 2011

Review first published: Issue 8, 2012

\section{CONTRIBUTIONS OFAUTHORS}

Hugo Cogo-Moreira, who is an expert in biostatistics and epidemiological studies and a musician (bachelor of piano), took the lead in drafting the review. He received advice from epidemiologists with expertise in systematic review methodology and meta-analysis, Professor Jair Mari and Professor George Ploubidis, Régis Andriolo, and from Professor Clara Brandão de Ávila (speech and hearing pathology therapist) and Latife Yazigi (psychologist), who have expertise in working with children who have dyslexia or other learning disorders.

\section{DECLARATIONSOF INTEREST}

- Hugo Cogo-Moreira - receives a monthly doctoral fellowship from CAPES (Co-ordination for the Improvement of Higher Education Personnel or Coordenação de Aperfeiçoamento de Pessoal de Nível Superior), an organization linked with the Brazilian Ministry of Education, to conduct this systematic review together with a randomized clinical trial about the effectiveness of music education in dyslexic children.

- Régis B Andriolo - none known.

- Latife Yazigi - none known.

- George Ploubidis - none known.

- Clara Regina Brandão de Ávila - none known.

- Jair Mari - partial funding received from the National Research Council (Conselho Nacional de Pesquisa - CNPq) and a foundation directed to funding projects on dyslexia (Instituto ABCD).

\section{SOURCES OF SUPPORT}

\section{Internal sources}

- CAPES, Brazil.

In Brazil, CAPES (The Co-ordination Foundation for the Improvement of Higher Education Personnel) offers scholarships for graduate Brazilian Students.

\section{External sources}

- No sources of support supplied 


\section{INDEX TERMS}

\section{Medical Subject Headings (MeSH)}

*Music; *Reading; Comprehension; Dyslexia [ ${ }^{*}$ rehabilitation]; Music Therapy [*education]

\section{MeSH check words}

Adolescent; Child; Humans 